\title{
Calcium Homeostasis in Articular Chondrocytes of Two Different Animal Species
}

\author{
Rachel White1, John Stanley Gibson ${ }^{2}$ \\ ${ }^{1}$ Equine Department, University Centre Myerscough College (University of Central Lancashire), Preston, UK \\ ${ }^{2}$ Department of Veterinary Medicine, University of Cambridge, Cambridge, UK \\ Email: rwhite@myerscough.ac.uk, jsg1001@cam.ac.uk
}

How to cite this paper: White, R. and Gibson, J.S. (2018) Calcium Homeostasis in Articular Chondrocytes of Two Different Animal Species. Open Journal of Veterinary Medicine, 8, 119-133.

https://doi.org/10.4236/ojvm.2018.88012

Received: July 24, 2018

Accepted: August 27, 2018

Published: August 30, 2018

Copyright (c) 2018 by authors and Scientific Research Publishing Inc. This work is licensed under the Creative Commons Attribution International License (CC BY 4.0).

http://creativecommons.org/licenses/by/4.0/

(c) (i) Open Access

\begin{abstract}
Introduction: Intracellular calcium concentration $\left(\left[\mathrm{Ca}^{2+}\right]_{\mathrm{i}}\right)$ is a critical parameter in cellular homeostasis, including articular chondrocytes. Perturbed $\left[\mathrm{Ca}^{2+}\right]_{\mathrm{i}}$ of chondrocytes may be associated with joint disease. The objective of the study was to compare large animal models for investigating $\mathrm{Ca}^{2+}$ homeostasis in chondrocytes. Materials and Methods: The gross anatomy of the metacarpophalangeal joint (MCP) of cattle and sheep was compared, along with the effect of various manoeuvres used to study the mechanisms of $\mathrm{Ca}^{2+}$ homeostasis in chondrocytes from load-bearing areas. The gross anatomy was observed before and after dissection, and internal architecture was examined after sectioning. Cartilage thickness was measured with a digital micrometer. Chondrocyte yield was determined after isolation. Chondrocytes were incubated with Fura- 2 and $\mathrm{Ca}^{2+}{ }_{i}$ followed in different extracellular conditions. A hypotonic shock (HTS) was used to mimic removal of a load. Results: The results showed that ovids and bovids were skeletally immature and aspects of $\mathrm{Ca}^{2+}$ homeostasis were similar. Ovine chondrocytes had higher resting fluorescence, consistent with elevated resting $\mathrm{Ca}^{2+}$ levels. Results from ion substitution experiments were consistent with a role for $\mathrm{Na}^{+} / \mathrm{Ca}^{2+}$ exchange, and swelling-induced $\mathrm{Ca}^{2+}$ enters into the cytoplasm via the plasma membrane and intracellular stores. Conclusions: $\mathrm{Ca}^{2+}$ homeostasis in chondrocytes from both species behaved in a similar manner to HTS and ion substitutions. Differences in resting $\left[\mathrm{Ca}^{2+}\right]_{\mathrm{i}}$ could be associated with species, stage of maturation, or Fura-2 itself and require further investigation. These findings contribute to our understanding of the physiology of articular cartilage in different species, and their potential use as models for studying joint disease in humans.
\end{abstract}

\section{Keywords}

Chondrocytes, Calcium, Fura-2, Hypotonic, Species 


\section{Introduction}

Due to a lack of human tissue availability, when investigating the physiology or pathophysiology of articular chondrocytes, it is necessary that appropriate animal models are used for comparative studies. The supply of cattle and sheep material from abattoirs is often more reliable than that from horses due to restricted age range. As a result there is considerable literature relating to these two large animal species and horses [1]-[7]. Bovids and ovids are quadruped, even toed ungulates that carry around $60 \%$ of their weight on their forelimbs [8] [9] [10] [11]. The differences in body size and mass make a comparison between these sedentary herbivores particularly interesting. The reasons for performing this comparative study were to determine the similarities and differences between the metacarpophalangeal (MCP) joints of bovids and ovids, and inform the cellular mechanisms responsible for $\mathrm{Ca}^{2+}$ homeostasis in articular chondrocytes. Ion homeostasis is a key regulator in the synthesis of cartilage matrix and an alteration in matrix metabolism is associated with osteoarthritis [12] [13]. Perturbed ion levels, including intracellular $\mathrm{pH}$ and intracellular $\mathrm{Ca}^{2+}$ levels in chondrocytes have been reported in humans with osteoarthritis [14].

The gross anatomy of the right (off-fore) MCP joint, internal architecture of the metacarpus (cannon bone) and thickness of the cartilage at load-bearing positions were studied. In addition, chondrocyte yield and intracellular $\mathrm{Ca}^{2+}$ levels (from both or one forelimbs) before and after a 50\% hypotonic shock (HTS) were investigated. HTS was used to mimic cellular swelling, which will occur after removal of mechanical load from joints, and was chosen as it has often been used as a paradigm in this context [15] [16] [17] [18] [19]. The resulting $\mathrm{Ca}^{2+}$ transients have been used to study mechanisms of $\mathrm{Ca}^{2+}$ recovery [17] [18] [19] [20] [21].

It was expected that the thickness of the cartilage would be greater in cattle compared to sheep due to allometric scaling [22] [23] but it is not known whether this may affect chondrocyte function or ion homeostasis, or if differences in age, maturity and life style could have an impact. Intracellular $\mathrm{Ca}^{2+} \mathrm{le}-$ vels of ovine chondrocytes have not previously been reported with the exception of preliminary findings [24], and the results of this study may have implications when applying findings from large animal model experiments to humans. The present study demonstrates many similarities and some differences in $\mathrm{Ca}^{2+}$ handling in the two species.

\section{Methods}

\subsection{Solutions and Chemicals}

Standard saline comprised (in $\mathrm{mM}$ ): $\mathrm{NaCl}$ (145), $\mathrm{KCl}$ (5), $\mathrm{CaCl}_{2}$ (2), $\mathrm{MgSO}_{4}$ (1), $\mathrm{D}^{+}$glucose (10) and 4-(2-hydroxyethyl)-1-piperazineethanesulfonic acid (HEPES, 10), $\mathrm{pH} 7.40$ at $37^{\circ} \mathrm{C}\left(290 \pm 5 \mathrm{mOsmol} \cdot \mathrm{kg}^{-1}\right)$. To investigate $\mathrm{Ca}^{2+}$-free conditions, $\mathrm{CaCl}_{2}$ was omitted and the $\mathrm{Ca}^{2+}$ chelator EGTA $(1 \mathrm{mM})$ added; for $\mathrm{Na}^{+}$-free saline, $N$-methyl-D-glucamine $\left(\mathrm{NMDG}^{+}\right)$replaced $\mathrm{Na}^{+}$. Cells were always prepared 
in standard saline and only exposed to these $\mathrm{Ca}^{2+}$ - or $\mathrm{Na}^{+}$-free solutions for a few minutes. Stock solutions of digitonin and Fura-2-AM were dissolved in DMSO. Fura-2 was obtained from Calbiochem (Merck, Darmstadt, Germany) and other chemicals such as Dulbecco's modified Eagle's medium (DMEM) from Sigma-Aldrich (Poole, UK). Ultrapure (Milli-Q, Merck Millipore, Mass, USA) water was used to dilute salines for a $50 \%$ HTS. Cell viability was not affected by any of these manoeuvres and remained at $>95 \%$ (as assessed by Trypan blue which is excluded from viable cells).

\subsection{Ethical Approval and Tissue Acquisition}

Ethical approval for the research was obtained from the Department of Veterinary Medicine (University of Cambridge). Bovine feet (from animals aged 18 36 months) and ovine feet ( $<12$ months) from humanely slaughtered animals were obtained from local, UK abattoirs. All tissue samples were refrigerated $\left(5^{\circ} \mathrm{C}\right)$ or frozen $\left(-20^{\circ} \mathrm{C}\right)$, and processed within $72 \mathrm{~h}$ of death.

\subsection{Internal Architecture of the Metacarpal Bone (Cannon Bone)}

The lower forelimb (below the carpus) of bovids, equids and ovids were skinned, cleaned and frozen $\left(-20^{\circ} \mathrm{C}, 48 \mathrm{~h}\right)$ before cutting through the MCP joint and cannon bone, longitudinally with a band saw.

\subsection{Measurement of Cartilage Thickness Overlying the Load-Bearing Area of the Metacarpophalangeal Joint}

After cleaning and thawing, a digital micrometer was used to measure the thickness of the cartilage overlying the load-bearing area. The cartilage was clearly visible and was measured from the articular surface to the delineation between cartilage and bone. Blinded measurements were taken from central positions at the lateral and medial trochlears, and at the upper most part of the condyles. The effects of freezing and thawing were not determined. Longitudinal slices through the frozen joint and cannon bone also allowed comparison of the internal architecture of the metacarpal bone of all species.

\subsection{Chondrocyte Isolation}

Immediately after collection, the MCP joints of bovids $(n=18)$ and ovids $(n=5)$ were skinned, cleaned and stored at $5^{\circ} \mathrm{C}$. The joints were opened aseptically in a flow hood within 72 hours of death. Full depth hyaline cartilage shavings from the MCP joint were taken at ambient $\mathrm{O}_{2}$ tension and placed in DMEM containing penicillin (100 IU. $\left.\mathrm{ml}^{-1}\right)$, streptomycin $\left(0.1 \mu \mathrm{g} \cdot \mathrm{ml}^{-1}\right)$ and fungizone $(2.5$ $\left.\mu \mathrm{g} \cdot \mathrm{ml}^{-1}\right)$. They were incubated at $37^{\circ} \mathrm{C}, 5 \% \mathrm{CO}_{2}$ for $16-18 \mathrm{~h}$ at $20 \% \mathrm{O}_{2}$ whilst matrix was digested with $0.1 \%(\mathrm{w} / \mathrm{v})$ collagenase type $\mathrm{I}(16 \mathrm{~h})$ in cattle and sheep. Isolated chondrocytes were re-suspended in DMEM lacking phenol red (which is known to affect $\mathrm{pH}$ measurements and subsequently $\mathrm{Ca}^{2+}$ levels) and a cell count performed using a haemocytometer. Cell viability was determined by the Trypan Blue exclusion test, at $>95 \%$ before and after experimental regimes 
(within $3 \mathrm{~h}$ post isolation).

\subsection{Fluorimetric Measurements of Intracellular Calcium Levels}

Intracellular $\mathrm{Ca}^{2+}$ levels $\left(\left[\mathrm{Ca}^{2+}\right]_{\mathrm{i}}\right.$ ) from multiple individuals (bovids $n=9$ or $n=$ 4, ovids $n=3$ or $n=4$ ) were measured using Fura-2 [17] [18]. Chondrocytes were incubated with $5 \mu \mathrm{M}$ Fura-2-AM for $30 \mathrm{~min}$ at room temperature followed by $15 \mathrm{~min}$ at $37^{\circ} \mathrm{C}$. The chondrocyte suspension was then centrifuged and washed once, and then resuspended in the appropriate experimental saline at a final dilution of $10^{6}$ cells $\cdot \mathrm{ml}^{-1}$. They were transferred to a cuvette in a thermostatically regulated fluorimeter (F-2000 Fluorescence Spectrophotometer, Hitachi) and experiments were completed within $3 \mathrm{~h}$ of isolation. Fura- 2 was alternately excited at $340 \mathrm{~nm}$ and $380 \mathrm{~nm}$, and emission intensity was measured at $510 \mathrm{~nm}$ for $300 \mathrm{~s}$. The chondrocytes were subjected to a 50\% HTS at $60 \mathrm{~s}$. The $340: 380 \mathrm{~nm}$ fluorescence ratio (R) was converted to $\mathrm{Ca}^{2+}$ concentration (nM) using the calibration equation [25]:

$$
\left[\mathrm{Ca}^{2+}\right]_{i}=K_{d} \times\left[\left(R-R_{\min }\right) /\left(R_{\max }-R\right)\right] \times\left(S_{f 2} / S_{b 2}\right)
$$

The dissociation $\left(\mathrm{K}_{\mathrm{d}}\right)$ of Fura-2 was taken as $224 \mathrm{mM}$ although this may alter with different intracellular environments. $\mathrm{R}$ is the $340: 380 \mathrm{~nm}$ fluorescence ratio of the indicator at an unknown $\left[\mathrm{Ca}^{2+}\right] . \mathrm{R}_{\min }$ is the ratio in the absence of $\mathrm{Ca}^{2+}$ and $\mathrm{R}_{\max }$ is the maximum fluorescence ratio at saturating $\left[\mathrm{Ca}^{2+}\right]$. The $\mathrm{S}_{\mathrm{f} 2} / \mathrm{S}_{\mathrm{b} 2}$ is the ratio of the long wavelength $(380 \mathrm{~nm})$ in the absence of $\mathrm{Ca}^{2+}\left(\mathrm{S}_{\mathrm{f} 2}\right)$ and presence of $\mathrm{Ca}^{2+}\left(\mathrm{S}_{\mathrm{b} 2}\right)$. The autofluorescence in the absence of dye at the 340 and $380 \mathrm{~nm}$ wavelength was subtracted in order to calculate $\left[\mathrm{Ca}^{2+}\right]_{\mathrm{i}}[26]$.

\subsection{Statistics}

Results are presented as the means \pm standard error of the mean (SEM) for $n$ individual animals unless otherwise stated, and statistical analysis performed by the GraphPad Prism version 6.0 for Windows (GraphPad Software, San Diego, California, USA). Gross anatomy: Multiple animal joints were used for all measurements (bovids $n=6$, ovids $n=5$ ). Cartilage thickness: The average cartilage thickness overlying the medial and lateral trochlears and condyles from the same animals was calculated, and the standard deviation (SD) and SEM determined. An Independent $\mathrm{t}$-test was employed to ascertain statistical significance $(P<$ $0.05)$ between cartilage thickness at these points in different species. $\mathrm{Ca}^{2+}{ }_{i}$ levels: Each experiment was repeated in triplicate using tissue from individual animals (bovids $n=9, n=4, n=4$ and ovids $n=3, n=4$ and $n=4$ respectively for chondrocytes suspended in normocalcaemic, $\mathrm{Ca}^{2+}$-free or $\mathrm{Na}^{+}$-free salines). However, chondrocytes in suspension tend to descend to the bottom of eppenddorfs over a period of time, and despite attempts to resuspend them this can cause currents that result in a reduction in the number of chondrocytes placed in the cuvette and subsequently, a decrease in the fluorescence signal emitted. This has been reported previously in similar studies and resulted in the 
data being pooled for analysis. To calculate $\mathrm{Ca}^{2+}{ }_{\mathrm{i}}$ levels, numerical analysis of ratiometric measurements and $\left[\mathrm{Ca}^{2+}\right]_{\mathrm{i}}$ was performed. The autofluorescence was measured and deducted from 340 and $380 \mathrm{~nm}$ wavelength recordings and controls were taken. The results were compared before and after HTS in each case for chondrocytes suspended in normocalcaemic saline (control group), or $\mathrm{Ca}^{2+}$-free and $\mathrm{Na}^{+}$-free salines (test groups). The mean, percentage increase, SD and SEM were determined. The Student's paired t-test was utilised to determine statistical significance $(P<0.05)$ on changes of $\left[\mathrm{Ca}^{2+}\right]_{\mathrm{i}}$ following HTS within control and test groups of the same species. The Independent t-test was employed to ascertain statistical significance $(P<0.05)$ between resting $\mathrm{Ca}^{2+}$ levels and those following HTS for both control and test groups of the same species (dependant on saline) and different species. For example, the resting $\left[\mathrm{Ca}^{2+}\right]_{\mathrm{i}}$ of chondrocytes suspended in standard saline and the resting $\left[\mathrm{Ca}^{2+}\right]_{i}$ of chondrocytes suspended in $\mathrm{Ca}^{2+}$-free saline of one species, or both. The mean \pm SEM was expressed in all histograms and statistical significance denoted with an asterisk ${ }^{*}$ ) or hash sign (\#).

\section{Results}

\subsection{Gross Anatomy, Internal Architecture and Cartilage Thickness}

The distal metacarpal bones of cattle (18 - 36 months) and sheep were very similar in structure (Figure 1 and Figure 2). The growth plate was evident in the bones of individual bovids $(n=6)$ and ovids $(n=5)$ indicative of an immature animal. The thickness of cartilage, measured from the articular surface to the subchondral bone was greater in the load-bearing areas of the proximal MCP joint of cattle compared to sheep. The average cartilage thickness was much thinner covering the condyles of cattle $(P<0.001$, Independent t-test) and sheep $(P<0.003$, Independent $\mathrm{t}$-test $)$ compared to cartilage at the trochlears. Closer examination showed that the thickness of cartilage appeared to vary across the joint of all bovids and ovids in a similar manner (Figure 3). In cattle, for example, the cartilage of the right MCP joint was thicker $(0.65 \mathrm{~mm})$ at the abaxial lateral trochlear (outermost), decreased to a similar thickness at the axial lateral and the axial medial trochlears $(\sim 0.5 \mathrm{~mm})$ and increased $(0.6 \mathrm{~mm})$ at the abaxial medial trochlears (innermost). Measurement of cartilage thickness at the medial $(0.37 \mathrm{~mm})$ and lateral $(0.26 \mathrm{~mm})$ condyles showed the opposite pattern.

\subsection{Chondrocyte Isolation and Cell Yield}

Chondrocytes from cattle and sheep articular cartilage were isolated overnight by collagenase digestion $(0.1 \% \mathrm{w} / \mathrm{v})$ Following this procedure, the number of chondrocytes from $1 \mathrm{~g}$ of shavings obtained was similar in bovine $\left(1 \pm 0.2 \times 10^{7}\right.$, $n=18)$ and ovine $\left(1.2 \pm 0.3 \times 10^{7}, n=5\right)$ tissue. Cell viability, ascertained by the Trypan Blue exclusion test was found to be $>95 \%$ for both species. There were no noticeable differences in the staining or size of chondrocytes. 


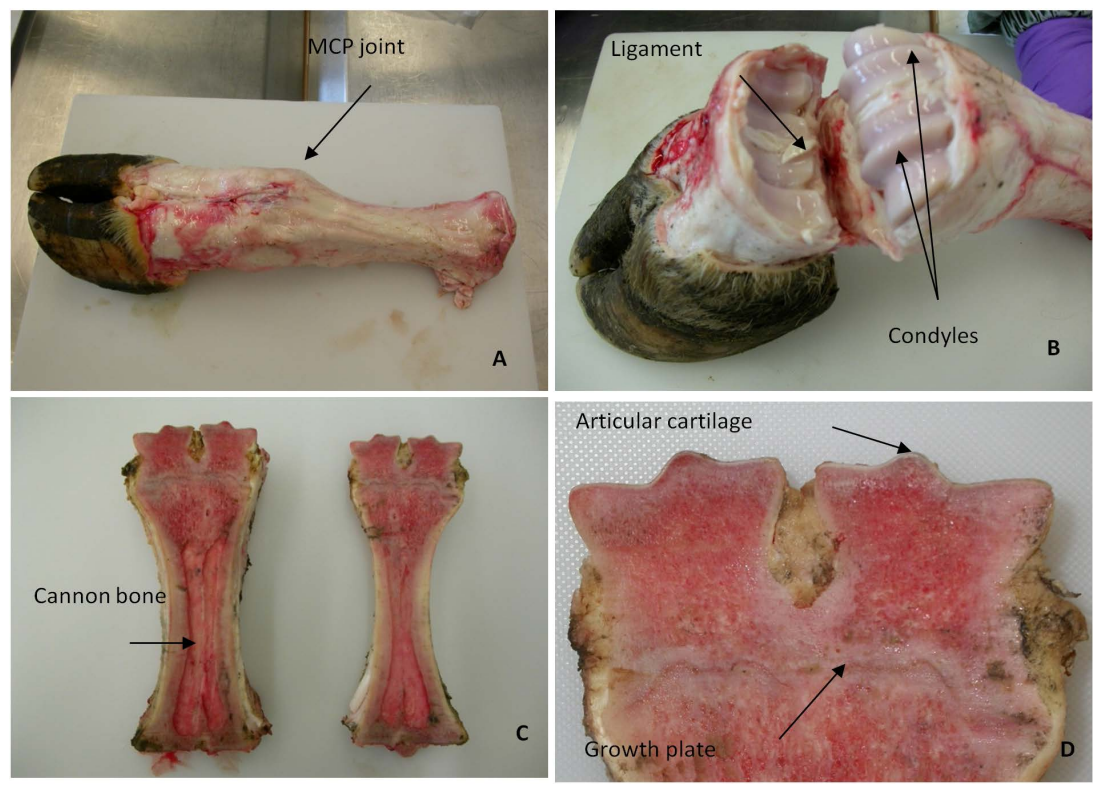

Figure 1. (A)-(D) The metacarpophalangeal (MCP) joint of a bovid. The limb below the carpus joint was skinned and washed prior to dissection. The MCP joint was opened fully by cutting through the interdigital ligament that runs through the centre of the joint exposing the trochlear surfaces and condyles on either side. The load-bearing surface area of the joint was measured and the metacarpal bone was cut in half sagittally, revealing the growth plate at the distal end of the bone. This also allowed the thickness of the articular cartilage to be measured. The images taken from an individual animal are representative of the MCP joint of others $(n=6)$.
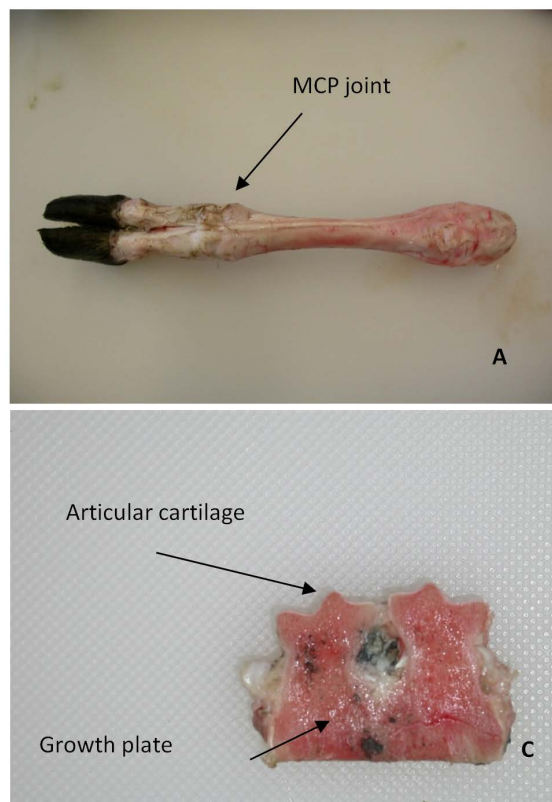

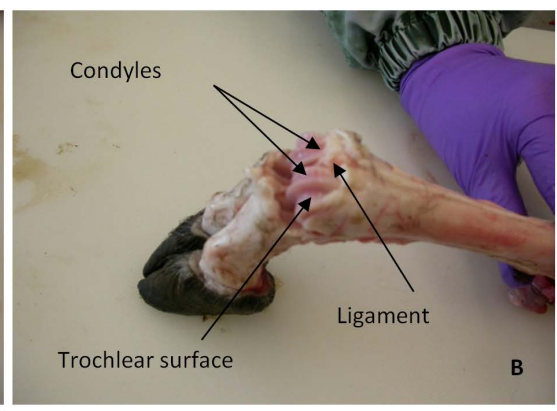

B

Figure 2. (A)-(C) The metacarpophalangeal (MCP) joint of an ovid. Samples were prepared as described in the legend to Figure 1. The structure of the ovine lower limb is similar to that of the bovine limb with growth plates at the distal end of the metacarpal bone evident in both species. The surface area and the thickness of cartilage overlying the load-bearing region were measured. The images taken of an individual animal are representative of the MCP joint of other sheep $(n=5)$. 


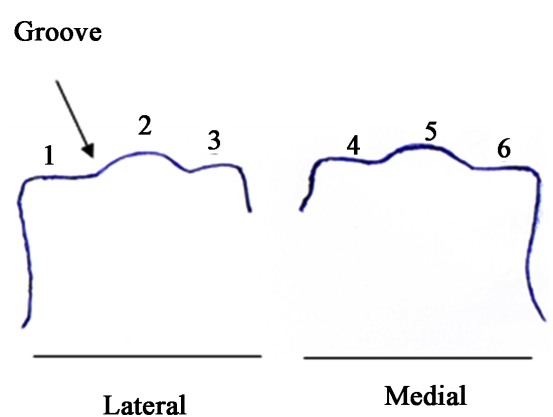

(a)

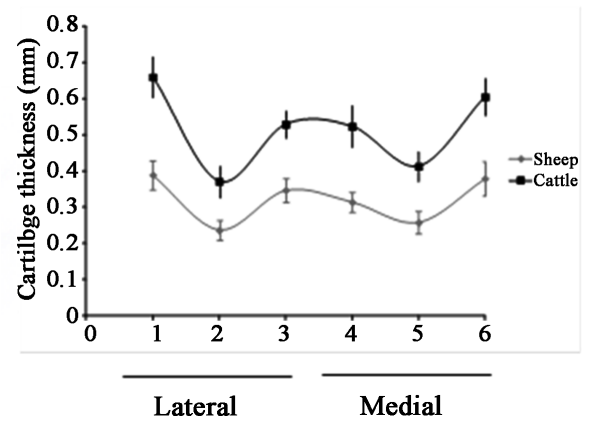

(b)

Figure 3. (a) and (b) Schematic representation of the off-fore distal metacarpophalangeal (MCP) joint of bovids and ovids. (a) Each number represents the lateral or medial condyles or trochlears. 1, abaxial lateral trochlear, 3, axial lateral trochlear, 4 , axial medial trochlear, 6, abaxial medial trochlear, 2, lateral condyle and 5, medial condyle; (b) Cartilage thickness across the off-fore distal MCP joint of cattle and sheep. The MCP joint of cattle and sheep was halved and the cartilage thickness measured at the lateral and medial condyles, and the axial and abaxial lateral and medial trochlears (as shown above) were measured electronically with a micrometer. Data are presented as the means \pm SEM for cattle $(n=6)$ and sheep $(n=5)$.

\subsection{Calcium Homeostasis and the Effect of Hypotonic Shock}

The intracellular $\mathrm{Ca}^{2+}$ levels of bovine and ovine chondrocytes were followed fluorimetrically before and after HTS over a $300 \mathrm{~s}$ time course. This is shown in representative traces in normocalcaemic $\left(2 \mathrm{mM} \mathrm{Ca}^{2+}\right)$ saline and also in the absence of $\mathrm{Ca}^{2+}$ and $\mathrm{Na}^{+}$(Figure 4(a) and Figure 4(b)). Mean values are presented in normocalcaemic saline, $\mathrm{Ca}^{2+}$-free and $\mathrm{Na}^{+}$-free salines in Figures 5-7 below. Before HTS, the intracellular $\mathrm{Ca}^{2+}$ levels were constant. The mean steady state level of $\mathrm{Ca}^{2+}$ in bovine ( $\left.60 \pm 7 \mathrm{nM}, n=9\right)$ chondrocytes was lower than in ovine chondrocytes (Figure 5). The $\left[\mathrm{Ca}^{2+}\right]_{i}$ of ovine chondrocytes was much higher $(160 \pm 27 \mathrm{nM}, n=3)(P<0.05)$. HTS was given after $60 \mathrm{~s}$ and there was an immediate rise in $\mathrm{Ca}^{2+}$ levels in both species until plateau values were reached. The percentage rise in $\mathrm{Ca}^{2+}$ was lower in bovine chondrocytes $(45 \pm 7 \%)$ and ovine chondrocytes $(80 \% \pm 20 \%)$, with $P<0.001$ and $P<0.002$ (Student's paired t-test) respectively, compared to resting steady state values. A similar percentage increase means more $\mathrm{Ca}^{2+}$ enters the cytoplasm and, or is released by intracellular stores when the resting intracellular $\mathrm{Ca}^{2+}$ level is higher. After this point, a plateau was reached and maintained as $\mathrm{Ca}^{2+}$ entry and efflux were balanced. $\mathrm{Ca}^{2+}$ levels then began to fall after $\sim 200 \mathrm{~s}$ (shown in Figure 4(b) for ovine chondrocytes; but similarly for bovine-data not shown) as $\mathrm{Ca}^{2+}$ was removed from chondrocytes and steady state levels were restored. Thus, $\left[\mathrm{Ca}^{2+}\right]_{\mathrm{i}}$ in chondrocytes from both species behaved in a similar way to hypotonicity.

\subsection{The Effect of Removing Extracellular Calcium on Intracellular Calcium Concentration before and after Hypotonic Shock}

$\mathrm{Ca}^{2+}$ influx from the extracellular fluid was investigated in bovine $(n=4)$ and 
ovine $(n=4)$ chondrocytes by suspending them in $\mathrm{Ca}^{2+}$-free saline $\left(\mathrm{Ca}^{2+}\right.$ replaced by $1 \mathrm{mM}$ EGTA). The absence of $\mathrm{Ca}^{2+}$ caused an immediate reduction in the mean steady state $\mathrm{Ca}^{2+}$ levels. For bovine chondrocytes, a significant reduction of $50 \%$ was observed $(P<0.001$, Independent t-test; Figure 6$)$. In ovine

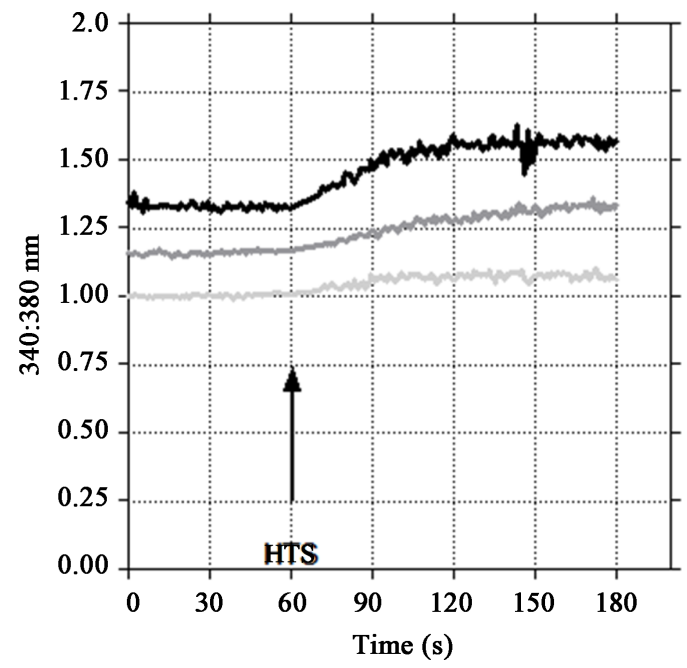

(a)
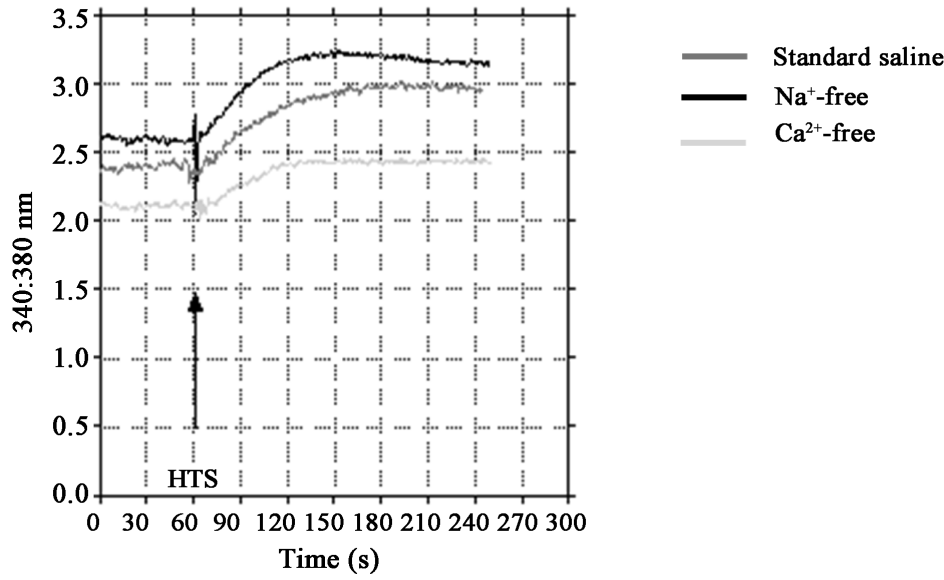

(b)

Figure 4. (a) and (b) Ratiometric recordings of $\mathrm{Ca}^{2+}$ in bovine and ovine chondrocytes and their response to hypotonic shock. Chondrocytes were isolated from cartilage slices by digestion with collagenase type 1 . Cells were suspended at a concentration of $1 \times$ $10^{6} \cdot \mathrm{ml}^{-1}$, incubated with Fura-2-AM $\left(5 \mu \mathrm{M}, 30\right.$ min room temperature, $\left.15 \min 37^{\circ} \mathrm{C}\right)$, and then suspended in three different solutions (standard saline containing $2 \mathrm{mM} \mathrm{Ca}^{2+}$, $\mathrm{Ca}^{2+}$-free saline or $\mathrm{Na}^{+}$-free saline). Intracellular $\mathrm{Ca}^{2+}$ levels were followed fluorimetrically before and after a 50\% HTS (60 s): (a) bovine, and (b) ovine chondrocytes. The intensity of the light emitted at $510 \mathrm{~nm}$ in response to excitation at 340 or $380 \mathrm{~nm}$ is given ratiometrically $(340: 380 \mathrm{~nm})$. These are single traces representative of $>5$ others. Steady state, resting $\mathrm{Ca}^{2+}$ levels were recorded for $60 \mathrm{~s}$ when a HTS was given, resulting in an immediate rise in $\mathrm{Ca}^{2+}$ levels in both species until a plateau was reached and maintained as $\mathrm{Ca}^{2+}$ entry and efflux were balanced. $\mathrm{Ca}^{2+}$ levels then began to fall after $\sim 200 \mathrm{~s}$ (shown in (b) for ovine chondrocytes; but similarly for bovine chondrocytes-data not shown) as $\mathrm{Ca}^{2+}$ was removed from chondrocytes and steady state levels were restored. 


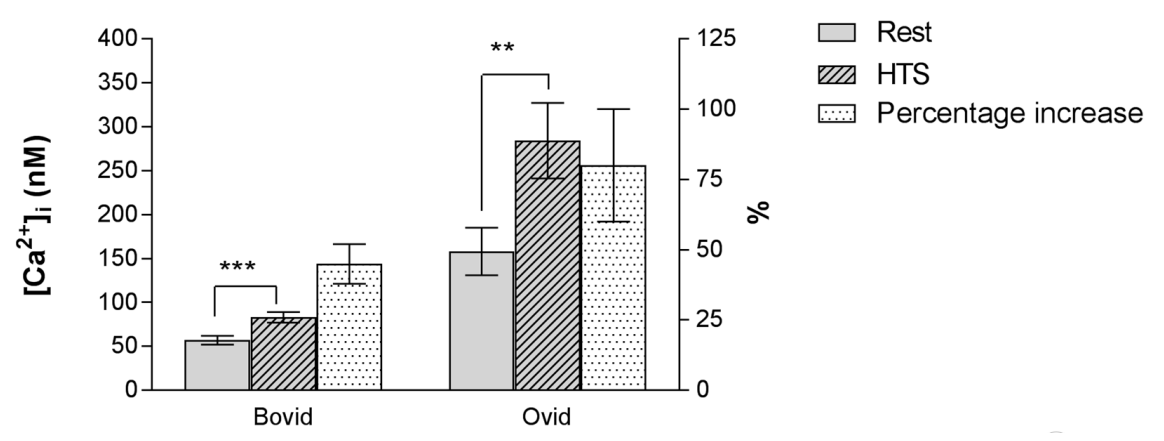

Figure 5. Comparison of resting intracellular $\mathrm{Ca}^{2+}$ concentration of bovine and ovine chondrocytes and response to hypotonic shock. Bovine and ovine chondrocytes were prepared as described in the legend to Figure 4. $\mathrm{Ca}^{2+}$ levels were measured fluorimetrically for $180 \mathrm{~s}$ and chondrocytes were subjected to a 50\% HTS at $60 \mathrm{~s}$. Ratiometric measurements were converted into a $\mathrm{Ca}^{2+}$ concentration (nM). Histograms represent means \pm SEM for $n=9$ and 3 for bovids and ovids respectively. ${ }^{\star * \star} P<0.001,{ }^{\star *} P<0.002$.

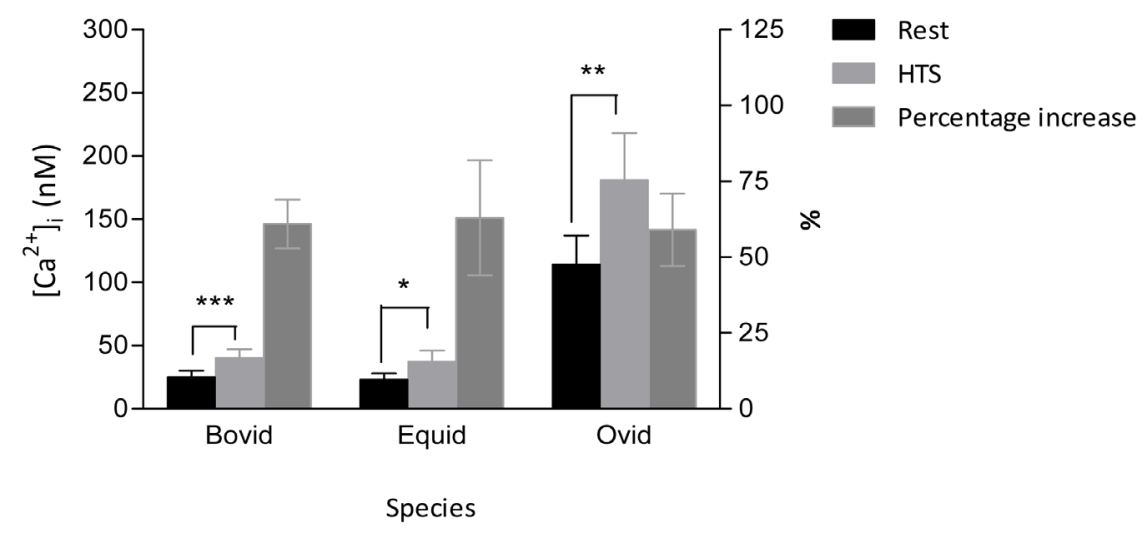

Figure 6. Effect of $\mathrm{Ca}^{2+}$-free saline on intracellular $\mathrm{Ca}^{2+}$ concentration of chondrocytes from different species and response to 50\% HTS. Bovine and ovine chondrocytes were prepared as described in the legend to Figure 4. $\mathrm{Ca}^{2+}$ levels were measured fluorimetrically for $180 \mathrm{~s}$ and chondrocytes were given a HTS (60 s). Ratiometric measurements were converted into a $\mathrm{Ca}^{2+}$ concentration (nM). Histograms represent means $\pm \mathrm{SEM}$ for $n$ $=4$ for bovids and ovids. ${ }^{\star * *} P<0.001,{ }^{\star} P<0.04$.

chondrocytes, a reduction of $30 \%$ was observed in response to suspension in $\mathrm{Ca}^{2+}$-free saline, although the change was not significant. Notwithstanding the absence of extracellular $\mathrm{Ca}^{2+}$, HTS evoked a rise in intracellular $\mathrm{Ca}^{2+}$ levels, by approximately $60 \%$ in both species $(P<0.04$, Student's paired t-test; Figure 6$)$. The absolute magnitudes of the $\mathrm{Ca}^{2+}$ responses elicited by HTS in chondrocytes from both species, however, were lower than those in controls in the presence of extracellular $\mathrm{Ca}^{2+}$. The percentage rise for bovine chondrocytes was slightly higher than that recorded in the presence of extracellular $\mathrm{Ca}^{2+}$, whilst the rise was reduced in ovine chondrocytes.

\subsection{The Effect of Removing Extracellular Sodium on Intracellular Calcium Concentration before and after Hypotonic Shock}

Experiments were performed to investigate the function and role of extracellular 
$\mathrm{Na}^{+}$in maintaining $\left[\mathrm{Ca}^{2+}\right]_{\mathrm{i}}$ in bovine and ovine chondrocytes. In bovids and ovids, the suspension of chondrocytes in $\mathrm{Na}^{+}$-free saline $\left(\mathrm{Na}^{+}\right.$replaced by $145 \mathrm{mM}$ $\mathrm{NMDG}^{+}$) caused a rise in the steady state resting $\mathrm{Ca}^{2+}$ levels in comparison to controls (Figure 7). $\mathrm{Ca}^{2+}$ levels in bovine chondrocytes ( $\left.80 \pm 12 \mathrm{nM}, n=4\right)$ were lower than in ovine chondrocytes. $\mathrm{Ca}^{2+}$ levels in ovine chondrocytes $(190 \pm 19$ $\mathrm{nM}, n=4)$ were much higher $(P<0.007$, Independent t-test, compared to controls in standard saline). In response to HTS, $\mathrm{Ca}^{2+}$ levels increased to a greater extent than controls suspended in standard saline in the presence of extracellular $\mathrm{Na}^{+}$in both species (all $P<0.03$, Student's paired t-test). Although the percentage rise in $\mathrm{Ca}^{2+}$ following HTS was higher in bovine $(90 \% \pm 24 \%)$ chondrocytes compared to ovine $(70 \% \pm 12 \%)$ chondrocytes, these differences were not statistically significant.

\section{Discussion}

The present study provides a comparison of the architecture of the MCP joints of two herbivores (cattle and sheep) together with $\mathrm{Ca}^{2+}$ homeostasis in articular chondrocytes. These large animals represent potential model species for investigating the pathophysiology of joint disease in humans, from which tissue is much less readily available. $\mathrm{Ca}^{2+}$ homeostasis was qualitatively similar in both species when ratiometric recordings are taken into consideration too. The results are consistent with a role for $\mathrm{Ca}^{2+} / \mathrm{Na}^{+}$exchange in reduction of intracellular $\mathrm{Ca}^{2+}$, with the elevation in $\left[\mathrm{Ca}^{2+}\right]_{\mathrm{i}}$ following hypotonic shock being mediated by both $\mathrm{Ca}^{2+}$ entry across the plasma membrane and release from intracellular stores.

The main difference in joint architecture between the two species was the stage of skeletal maturation. Epiphyseal growth plates were still present in both

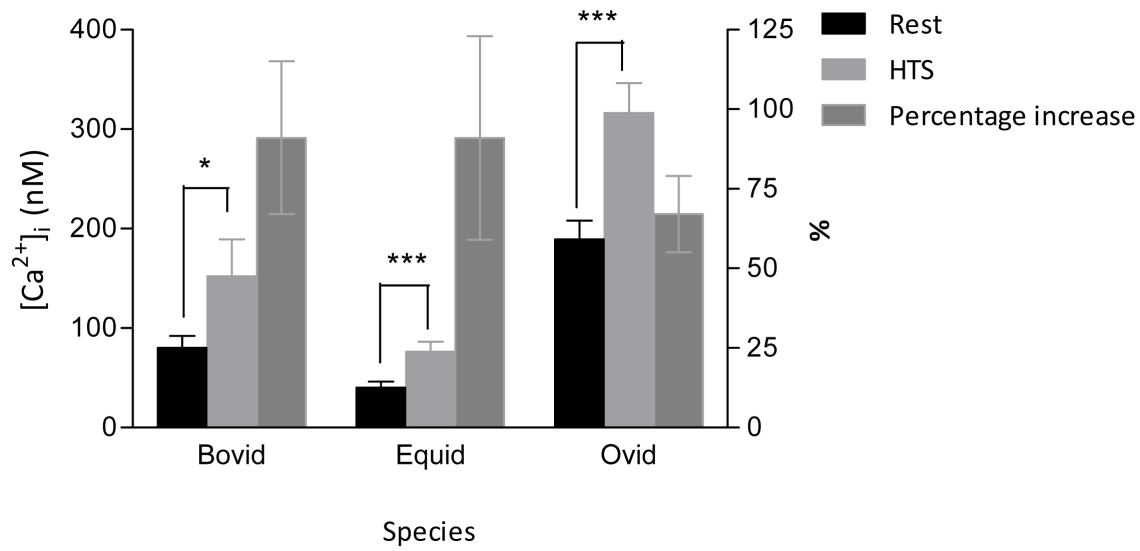

Figure 7. Effect of $\mathrm{Na}^{+}$-free saline on intracellular $\mathrm{Ca}^{2+}$ concentration of chondrocytes from different species and response to hypotonic shock. Bovine and ovine chondrocytes were prepared as described in the legend to Figure 4. $\mathrm{Ca}^{2+}$ levels were measured fluorimetrically for $180 \mathrm{~s}$ and chondrocytes were given a 50\% HTS at $60 \mathrm{~s}$. Ratiometric measurements were converted into a $\mathrm{Ca}^{2+}$ concentration (nM). Histograms represent means \pm SEM for $n=4$ for bovids and ovids. ${ }^{* *} P<0.002,{ }^{\star} P<0.03$. 
cattle and sheep, indicative of their skeletal immaturity. Longitudinal growth of the metacarpal bone continues until 6 months of age in sheep and 16 months of in age in cattle [27] and varies in other species. Cartilage from cattle is often used for this type of study and reported to be from skeletally mature animals but clearly this is not the case, and maturation may well have an impact on the intracellular $\mathrm{Ca}^{2+}$ levels. Also, cessation of longitudinal bone growth is not concomitant with maturation of the articular cartilage which may reach maturity before or after longitudinal bone growth stops in different species, and functional adaptation will have an effect, particularly in horses which tend to be used for athletic purposes [28]. In both species, chondrocytes were arranged perpendicularly to the articular surface, a functional adaptation to the load experienced (results not shown). In a similar way, thickness of articular cartilage has been shown to depend on extent of load bearing.

$\mathrm{Ca}^{2+}$ homeostasis of articular chondrocytes appeared similar across bovids and ovids. Thus $\left[\mathrm{Ca}^{2+}\right]_{\mathrm{i}}$ fell on removal of extracellular $\mathrm{Ca}^{2+}$, indicative of entry across the plasma membrane. Removal of extracellular $\mathrm{Na}^{+}$led to elevation of $\left[\mathrm{Ca}^{2+}\right]_{\mathrm{i}}$ implying active $\mathrm{Na}^{+} / \mathrm{Ca}^{2+}$ exchange (NCE) operating to remove intracellular $\mathrm{Ca}^{2+}$. HTS which mimics chondrocyte unloading caused $\left[\mathrm{Ca}^{2+}\right]_{\mathrm{i}}$ to rise, over a 60 $s$ timescale. The rise in $\mathrm{Ca}^{2+}$ was greater in the presence of extracellular $\mathrm{Ca}^{2+}$ consistent with a role for $\mathrm{Ca}^{2+}$ entry from extracellular fluid, likely through stretch-activated $\mathrm{Ca}^{2+}$ channels [4]. A role for TRPV channels has been proposed in this context [29]. $\mathrm{Ca}^{2+}$ transients were still apparent; however, when extracellular $\mathrm{Ca}^{2+}$ was removed, implying the release of $\mathrm{Ca}^{2+}$ also occurred from intracellular stores. A role for thapsigargin-sensitive stores has been previously [4] [18] [19] and observed in our unpublished observations on bovine and equine chondrocytes.

Quantitative differences were observed between the two species. The steady state, resting $\left[\mathrm{Ca}^{2+}\right]_{i}$ of bovine articular chondrocytes taken from the MCP joint of the fore limbs was $60 \pm 5 \mathrm{nM}$. This is considerably less than $100 \mathrm{nM}$ recorded in previous experiments [18], but similar to $\left[\mathrm{Ca}^{2+}\right]_{\mathrm{i}}$ of $50 \mathrm{nM}$ in cultured chondrocytes taken from the hind limbs of cattle [4]. The difference may be caused by a number of factors such as variations in isolation procedures, $\mathrm{pH}$ during the isolation procedure [30], choice of fluorescent probe and loading. Other considerations include type of breed, sex, age and limbs used, but these are likely to be more standardised in tissue from abattoir sources. Cell yield is also important as high cell density leads to acidification of the extracellular medium during culture, which would increase $\left[\mathrm{Ca}^{2+}\right]_{\mathrm{i}}[30]$.

$\left[\mathrm{Ca}^{2+}\right]_{\mathrm{i}}$ of ovine chondrocytes has not been reported previously. In this study, ovine chondrocytes appeared to have a much higher $\left[\mathrm{Ca}^{2+}\right]_{i}$ than bovine chondrocytes. Three possibilities may result in this and require further investigation. First, it could be due to differences in the structure, function and metabolism of chondrocytes from immature and mature articular cartilage [31] [32] [33]. Second, $\mathrm{Ca}^{2+}$ homeostasis in ovine chondrocytes could have a higher set point 
that is maintained by a mechanism involving intracellular stores which is less reliant on extracellular levels of $\mathrm{Ca}^{2+}$. Third, it is possible that Fura-2 behaves differently in ovine chondrocytes compared to bovine chondrocytes since the wavelength parameters used to calculate $\left[\mathrm{Ca}^{2+}\right]_{\mathrm{i}}$ differed from bovine chondrocytes and equine chondrocytes (unpublished data) suggesting that the dye behaved differently in this species. The loading of Fura-2-AM is affected by cellular differences in enzyme systems [34], temperature, $\mathrm{pH}$ and $\mathrm{O}_{2}$ tension [35]. The properties of the dye are affected by ionic strength, viscosity and protein concentration [26]. These factors may result in inaccurate and unreliable measurements of $\left[\mathrm{Ca}^{2+}\right]_{\mathrm{i}}$ using the calibration equation applied here [25]. The $\mathrm{R}_{\max }$ values and the concentration of $\mathrm{Ca}^{2+}$ required to reach saturation is affected by binding to high or low affinity sites and inadequate permeabilisation of the plasma membrane [36] [37]. Therefore, in vivo calibration of the $\mathrm{R}_{\max }$ may be more accurate [36] [38] [39]. Alternatively, omitting the $\mathrm{R}_{\max }$ and choosing excitation and emission wavelengths under certain conditions alters the calibration equation to produce a linear relationship between the fluorescence ratio and $\left[\mathrm{Ca}^{2+}\right]$, and requires only the constants $S_{f 2}, S_{b 2}$ and $R_{\min }$ [40]. Other researchers have used a calibration equation based on specific intensity values recorded at one excitation wavelength, or report the ratio only. The intracellular environment can also affect the $\mathrm{K}_{\mathrm{d}}$ of Fura- 2 and subsequently, the calculated $\left[\mathrm{Ca}^{2+}\right]_{\mathrm{i}}$ and calls for an in vivo calibration [38] [41] [42]. It was beyond the scope of this experiment to calculate $\mathrm{Kd}$.

\section{Conclusion}

In conclusion, chondrocytes from all species behave in similar manner to HTS and $\mathrm{Ca}^{2+}$ homeostasis appears to be controlled by similar transport mechanisms. It appears that there are species differences in $\left[\mathrm{Ca}^{2+}\right]_{\mathrm{i}}$ of chondrocytes that may be affected by the age and stage of maturation of an animal. Further investigations are required to ascertain the stage of musculoskeletal maturation in different species and compare the $\left[\mathrm{Ca}^{2+}\right]_{\mathrm{i}}$ of chondrocytes in mature and immature animals, and also $\left[\mathrm{Ca}^{2+}\right]_{\mathrm{i}}$ from diseased or damaged tissue to those of normal, healthy tissue. The behaviour of Fura- 2 could also account for these differences and further studies are required to elucidate this before ovids are used as a large animal model for investigating the physiology or pathophysiology of chondrocytes when access to human tissue is limited.

\section{Acknowledgements}

RW helped plan the experiments, carried them out, analysed the data and prepared the manuscript. JSG planned the experiments and helped write the manuscript. All authors have read and approved the final manuscript. This work was supported by a BBSRC Studentship held by RW. RW received financial support from University Centre Myerscough for the publication of this article. 


\section{Declaration of Conflicting Interests}

The Author(s) declare that there are no conflicts of interests.

\section{References}

[1] Yellowley, C.E., Jacobs, C.R., Li, Z.H., Zhou, Z. and Donahue, H.J. (1997) Effects of Fluid Flow on Intracellular Calcium in Bovine Articular Chondrocytes. American Journal of Physiology, 273, C30-C36. https://doi.org/10.1152/ajpcell.1997.273.1.C30

[2] Browning, J., Walker, R., Hall, A. and Wilkins, R. (1999) Modulation of Na+ x H+ Exchange by Hydrostatic Pressure in Isolated Bovine Articular Chondrocytes. Acta Physiologica Scandinavica, 166, 39-45. https://doi.org/10.1046/j.1365-201x.1999.00534.x

[3] Guilak, F., Zell, R.A., Erickson, G.R., Grande, D.A., Rubin, C.T., McLeod, K.J. and Donahue, H.J. (1999) Mechanically Induced Calcium Waves in Articular Chondrocytes Are Inhibited by Gadolinium and Amiloride. Journal of Orthopaedic Research, 17, 421-429. https://doi.org/10.1002/jor.1100170319

[4] Yellowley, C.E., Hancox, J.C. and Donahue, H.J. (2002) Effects of Cell Swelling on Intracellular Calcium and Membrane Currents in Bovine Articular Chondrocytes. Journal of Cell Biochemistry, 86, 290-301. https://doi.org/10.1002/jcb.10217

[5] Endres, M., Neumann, K., Zhou, B., Freymann, U., Pretzel, D., Stoffel, M., Kinne, R.W. and Kaps, C. (2012) An Ovine in Vitro Model for Chondrocyte-Based Scaffold-Assisted Cartilage Grafts. Journal of Orthopaedic Surgery and Research, 7, 1. https://doi.org/10.1186/1749-799X-7-37

[6] Garcia, D., Giuseppe Longo, U., Vaquero, J., Forriol, F., Loppini, M.S., Khan, W. and Denaro, V. (2015) Amniotic Membrane Transplant for Articular Cartilage Repair: An Experimental Study in sHeep. Current Stem Cell Research Therapy, 10, 77-83. https://doi.org/10.2174/1574888X09666140710120012

[7] Power, J., Hernandez, P., Guehring, H., Getgood, A. and Henson, F. (2014) Intra-Articular Injection of rhFGF-18 Improves the Healing in Microfracture Treated Chondral Defects in an Ovine Model. Journal of Orthopaedic Research, 32, 669-676. https://doi.org/10.1002/jor.22580

[8] Raven, E.T. (1989) Cattle Footcare and Claw Trimming. Diamond Farm Book Pubns, Brighton.

[9] Bokko, B.P. and Chaudhari, S.U.R. (2001) Prevalence of Lameness in Sheep in the North East Region of Nigeria. International Journal of Agricultural Biology, 3, 519-521.

[10] Neveux, S., Weary, D.M., Rushen, J., Von Keyserlingk, M.A. and De Passillé, A.M. (2006) Hoof Discomfort Changes How Dairy Cattle Distribute Their Body Weight. Journal of Dairy Science, 89, 2503-2509. https://doi.org/10.3168/jds.S0022-0302(06)72325-6

[11] van der Tol, R., Somers, J., Weijs, W. and Stassen, E. (2006) Lameness in Cattle: Are We on the Wrong Track? Veterinary Sciences Tomorrow, 2006, 1-8.

[12] Martel-Pelletier, J., Boileau, C., Pelletier, J.P. and Roughly, P.J. (2008) Cartilage in Normal and Osteoarthritis Conditions. Best Practice \& Research: Clinical Rheumatology, 22, 351-384. https://doi.org/10.1016/j.berh.2008.02.001

[13] Wilkins, R.J. and Hall, A.C. (1995) Control of Matrix Synthesis in Isolated Bovine Chondrocytes by Extracellular and Intracellular pH. Journal of Cell Physiology, 164, 474-481. https://doi.org/10.1002/jcp.1041640305 
[14] Sanchez, J.C. and Lopez-Zapata, D.F. (2015) Effects of Adipokines and Insulin on Intracellular $\mathrm{pH}$, Calcium Concentration, and Responses to Hypo-Osmolarity in Human Articular Chondrocytes from Healthy and Osteoarthritic Cartilage. Cartilage, 6, 45-54. https://doi.org/10.1177/1947603514553095

[15] Browning, J.A. and Wilkins, R.J. (1998) The Characterisation of Mechanisms Regulating Intracellular $\mathrm{pH}$ in a Transformed Human Articular Chondrocyte Cell Line C-20/A4. Journal of Physiology P, 513, 54.

[16] O’Neill, W.C. (1999) Physiological Significance of Volume-Regulatory Transporters. American Journal of Physiology, 276, C995-C1011. https://doi.org/10.1152/ajpcell.1999.276.5.C995

[17] Sanchez, J. and Wilkins, C.R.J. (2003) Effects of Hypotonic Shock on Intracellular $\mathrm{pH}$ in Bovine Articular Chondrocytes. Comparative Biochemistry and Physiology $A, 135,575-583$.

[18] Sanchez, J.C. and Wilkins, C.R.J. (2003) Mechanisms Involved in the Increase in Intracellular Calcium Following Hypotonic Shock in Bovine Articular Chondrocytes. General Physiology and Biophysics, 22, 487-450.

[19] Wilkins, R.J., Fairfax, T., Davies, M.E., Muzyamba, M.C. and Gibson, J.S. (2003) Homeostasis of Intracellular $\mathrm{Ca}^{2+}$ in Equine Chondrocytes: Response to Hypotonic Shock. Equine Veterinary Journal, 35, 439-443. https://doi.org/10.2746/042516403775600541

[20] Hall, A.C., Horwitz, E.R. and Wilkins, R.J. (1996) The Cellular Physiology of Articular Cartilage. Exercise Physiology, 81, 435-545.

[21] White, R. and Gibson, J.S. (2010) The Effect of Oxygen Tension on Calcium Homeostasis in Bovine Articular Chondrocytes. Journal of Orthopaedic Surgery and Research, 5, 1-7. https://doi.org/10.1186/1749-799X-5-27

[22] Simon, W.H. (1970) Scale Effects in Animal Joints. 1. Articular Cartilage Thickness and Compressive Strain. Arthritis and Rheumatism, 13, 244-255. https://doi.org/10.1002/art.1780130305

[23] Schmidt-Nielsen, K. (1990) Animal Physiology. Cambridge University Press, Cambridge.

[24] White, R. and Gibson, J.S. (2017) Calcium Homeostasis in Articular Chondrocytes of Two Different Animal Species. Osteoarthritis and Cartilage, 25, S154.

[25] Grynkiewicz, G., Poenie, M. and Tsien, R.Y. (1985) A New Generation of $\mathrm{Ca}^{2+}$ Indicators with Greatly Improved Fluorescence Properties. Journal of Biological Chemistry, 260, 3440-3450.

[26] Williams, D.A. and Fay, F.S. (1990) Intracellular Calibration of the Fluorescent Calcium Indicator Fura-2. Cell Calcium, 11, 75-83. https://doi.org/10.1016/0143-4160(90)90061-X

[27] Kilborn, S.H., Trudel, G. and Uhthoff, H. (2002) Review of Growth Plate Closure Compared with Age at Sexual Maturity and Lifespan in Laboratory Animals. Contempary Topics in Laboratory Animal Science, 41, 21-26.

[28] Brommer, H., Brama, P.A., Laasanen, M.S., Helminen, H.J., Weeren, P.V. and Jurvelin, J.S. (2005) Functional Adaptation of Articular Cartilage from Birth to Maturity under the Influence of Loading: A Biomechanical Analysis. Equine Veterinary Journal, 37, 148-154. https://doi.org/10.2746/0425164054223769

[29] O’Conor, C.J., Leddy, H.A., Benefield, H.C., Liedtke, W.B. and Guilak, F. (2014) TRPV4-Mediated Mechanotransduction Regulates the Metabolic Response of Chondrocytes to Dynamic Loading. Proceedings of the National Academy of 
Sciences, 111, 1316-1321. https://doi.org/10.1073/pnas.1319569111

[30] Browning, J.A. and Wilkins, R.J. (2002) The Effect of Intracellular Alkalinisation on Intracellular $\mathrm{Ca}^{2+}$ Homeostasis in a Human Chondrocyte Cell Line. European Journal of Physiology, 444, 744-751. https://doi.org/10.1007/s00424-002-0843-8

[31] Webber, R.J., Malemud, C.J. and Sokoloff, L. (1977) Species Differences in Cell Culture of Mammalian Articular Chondrocytes. Calcified Tissue Research, 23, 61-66. https://doi.org/10.1007/BF02012767

[32] Bayliss, M.T., Howat, S., Davidson, C. and Dudhia, J. (2000) The Organization of Aggrecan in Human Articular Cartilage. Journal of Biological Chemistry, 275, 6321-6327. https://doi.org/10.1074/jbc.275.9.6321

[33] Giannoni, P., Crovace, A., Malpeli, M., Maggi, E., Arbico, R., Cancedda, R. and Dozin, B. (2005) Species Variability in the Differentiation Potential of in Vitro-Expanded Articular Chondrocytes Restricts Predictive Studies on Cartilage Repair Using Animal Models. Journal of Tissue Engineering, 11, 237-248. https://doi.org/10.1089/ten.2005.11.237

[34] Konishi, M. (1998) Cytoplasmic Free Concentrations of $\mathrm{Ca}^{2+}$ and $\mathrm{Mg}^{2+}$ in Skeletal Muscle Fibers at Rest and during Contraction. Japanese Journal of Physiology, 48, 421-438. https://doi.org/10.2170/jiphysiol.48.421

[35] Oliver, A.E., Baker, G.A., Fugate, R.D., Tablin, F. and Crowe, J.H. (2000) Effects of Temperature on Calcium-Sensitive Fluorescent Probes. Biophysical Journal, 78, 2116-2126. https://doi.org/10.1016/S0006-3495(00)76758-0

[36] Uto, A., Arai, H. and Ogawa, Y. (1991) Reassessment of Fura-2 and the Ratio Method for Determination of Intracellular $\mathrm{Ca}^{2+}$ Concentrations. Cell Calcium, 12, 29-37. https://doi.org/10.1016/0143-4160(91)90082-P

[37] Henke, W., Cetinsoy, C., Jung, K. and Loening, S. (1996) Nonmhyperbolic Calcium Calibration Curve of Fura-2: Implications for the Reliability of Quantitative $\mathrm{Ca}^{2+}$ Measurements. Cell Calcium, 20, 287-292. https://doi.org/10.1016/S0143-4160(96)90034-2

[38] Jiang, Y. and Julian, F.J. (1997) Pacing Rate, Halothane, and BDM Affect Fura 2 Reporting of $[\mathrm{Ca} 2+] \mathrm{i}$ in Intact Rat Trabeculae. American Journal of Physiology, 273, C2046-C2056. https://doi.org/10.1152/ajpcell.1997.273.6.C2046

[39] Brenowitz, S.D. and Regeh, W.G. (2002) Calcium Dependence of Retrograde Inhibition by Endocannabinoids at Synapses onto Purkinje Cells. Journal of Neuroscience, 23, 6373-6384. https://doi.org/10.1523/JNEUROSCI.23-15-06373.2003

[40] Palmer, B.M. and Moore, R.L. (2000) Excitation Wavelengths for Fura 2 Provide a Linear Relationship between $[\mathrm{Ca}(2+)]$ and Fluorescence Ratio. American Journal of Physiology-Cell Physiology, 279, C1278-C1284. https://doi.org/10.1152/ajpcell.2000.279.4.C1278

[41] Gomes, P.A., Bassani, R.A. and Bassani, J.M. (1998) Measuring [Ca2+] with Fluorescent Indicators: Theoretical Approach to the Ratio Method. Cell Calcium, 24, 17-26. https://doi.org/10.1016/S0143-4160(98)90085-9

[42] Thomas, D., Tovey, S.C., Collins, T.J., Bootman, M.D., Berridge, M.J. and Lipp, P. (2000) A Comparison of Fluorescent $\mathrm{Ca}^{2+}$ Indicator Properties and Their Use in Measuring Elementary and Global $\mathrm{Ca}^{2+}$ Signals. Cell Calcium, 28, 213-223. https://doi.org/10.1054/ceca.2000.0152 